\title{
Beitrag zur Kenntniss der bacteriellen Nucleoproteide.
}

\author{
Von
}

Dr. Gino Galeotti.

(Aus dem Laboratorium für allgemeine Experimentelpathologie des $\mathrm{R}^{0}$ Istituto di Studi superiori in Florenz.)

(Der Redaction zugegangen am 26. Februar 1S98.)

Die Kenntniss der chemischen Constitution der den Bacterienkörper bildenden Substanzen ist umso wichtiger, als eben diese Substanzen manchmal wirksame Impfstoffe bilden.

Eine Reihe dieser mit toxischen oder immunisirenden Eigenschaften ausgestatteten Substanzen ist unter dem etwas zu allgemeinen Namen der Proteine zusammengefasst worden, und ihr Studium von verschiedenen Gesichtspunkten der bacteriologischen Forschung aus hat eine beträchtliche Anzahl von Autoren beschäftigt.

Es wäre hier überflüssig, die Bibliographie der Frage zu berühren, und ich verweise hierïber den Leser auf die Handbücher der. Bacteriologie, insbesondere auf das Werk von Flügge "Die Mikroorganismen, Leipzig 1896,» welches sich mit derselben eingehend beschäftigt. Mir genügt es hier, einige der hauptsächlichsten Resultate anzuführen.

Die chemische Structur der Bacterien wurde von Vielen unabhängig von der Frage der Immunität studirt und es wurde gefunden, dass in dem Bacterienkörper die Proteinsubstanzen vorwiegen.

So sagt Cramer, ${ }^{1}$ ) dass im Bacterienkörper Proteinsubstanzen gegenüber den Kohlenhydraten in weitaus vorwiegender Menge verhanden sind. Proteinsubstanzen in Bac-

1) Archiv f. Hygiene, Bd. 16, S. 183. 
terien wurden ferner nachgewiesen von Nencki ${ }^{1}$ ) beim Milzbrandbacillus (Anthraxprotein); von Brieger beim Pneumococcus, von Hammerschlag ${ }^{2}$ ) und von Weyl $^{3}$ ) bei den Tuberkelbacillen.

Letzterer Autor beschäftigte sich eingehend mit der Feststellung einer speciellen Schleimsubstanz, die er aus den Koch'schen Bacillen mittelst Extraction durch Aetznatron gewann. Diese an Phosphor reiche, in Alkalien lösliche, durch verdünnte Säuren fällbare Substanz wurde von Weyl als eine Mucinart (Toxomucin) angesprochen und nur, indem er sagt: "Natürlich könnte man auch an ein Nucleoproteid denken» gibt er dem Zweifel Raum, dass es sich möglicher Weise auch um ein Nucleoproteid handeln könnte.

Die Forschungen Buchner's ${ }^{4}$ ) erwiesen die Anwesenheit von Proteinsubstanzen bei einer grossen Anzahl von Mikroorganismen, und die Eigenschaften dieser Subtsanzen (welche nach ihm denjenigen der Pflanzencaseine nahekommen) wurden von ihm für den Pyocyaneus und den Friedländer'schen Pneumobacillus gut präcisirt. Aus letzterem gewann er mittelst einer Methode, die der meinigen ähnelt, eine Proteinsubstanz, die er Pneumoprotein nannte. Er stellte fest, dass dieselbe die allgemeinen Reactionen der Albuminoidkörper gab: die Xanthoprotein-, die Millon'sche-, die Biuretreaction, und dass sie sich ausserdem mit Essig-Schwefelsäuremischung violett färbte. Die Substanz ist gleich gut löslich in Wasser, in concentrirten Säuren, in verdünnten Alkalien. Dieselbe coagulirte weder beim Kochen, noch durch Sättigung mit neutralen Salzen (mit Ausnahme von Magnesiumsulfat), gab mit den Salzen der Schwermetalle einen Niederschlag, ebenso mit Tannin und mit Alkohol. Buchner sagt, dass sich diese Substanz vom

1) Berl. chem. Berichte, Jahrg. 1884, S. 2605.

2) Bacteriologisch-chemische Untersuchungen über Tuberkelbacillen, Centralblatt f. innere Medicin, 1891, Nr. 1.

3) Zur Chemie und Toxicologie des Tuberkelbacillus, Deutsche med. Wochenschr. 1890, Bd. 256.

4) Buchner, Ueber pyogene Stoffe in der Bacterienzelle, Berl. klin. Wochenschr. 1890, Nr. 30. 
Mycoprotein vor Nencki und Schaffner ${ }^{1}$ ) unterscheidet, dagegen dem Anthraxprotein von Nencki (l. c.) und Doymont ${ }^{2}$ ) ähnlich ist. Seiner Ansicht nach hätte man es hier mit einem Albuminat zu thun. Auf allfällige immunisirende Eigenschaften untersucht er die Substanz nicht.

Schliesslich will ich noch die äusserst unbeständigen,von R. Pfeiffer ${ }^{3}$ ) aus dem Körper der Choleravibrionen gewonnenen Choleratoxine erwähnen, über deren chemische Constitution so gut wie nichts bekannt ist.

Im Allgemeinen jedoch enthalten diese verschiedenen Proteinsubstanzen bacteriellen Ursprunges Phosphor. Schon vor einiger Zeit erwähnte Gamaleya ${ }^{4}$ ) die toxischen Nucleoalbumine als einen Bestandtheils des Bacterienkörpers. Damals kam aber der Benennung der Nucleoalbumine ein anderer Begriff zu als heute. Schliesslich wurde nachgewiesen, dass der Bacterienkörper thatsächlich ächte Nucleine enthält, über deren Verhältniss zu den übrigen proteinartigen Bestandtheilen der Bacterien jedoch noch nichts verlautet. Vandevelde fand im Bacillus subtilis und Nishimura $\mathbf{a}^{5}$ ) in einem Bacillus des Trinkwassers ächte Nucleine. Letzterer Forscher wies die Nucleinnatur aus den im Körper dieses Bacteriums enthaltenen Phosphorverbindungen nach, da er aus denselben Nucleinbasen erhalten konnte. Er fand auf diese Weise 0,17\% Xanthin, 0,14\% Guanin, 0,08\% Adenin.

Als ich mich vor zwei Jahren mit dem Studium der aus Choleraculturen gewinnbaren immunisirenden Substanzen beschäftigte, ${ }^{6}$ ) konnte ich constatiren, dass das Impfvermögen Substanzen (sämmtliche selbstverständlich aus Choleraculturen gewonnen) zukommt, welche, obgleich alle der Gruppe der Proteine angehörig, verschiedene chemische Constitution be-

1) Journ. f. prakt. Chemie, Bd. XX, Heft 5, 1879.

2) Einige Beobachtungen über Milzbrandbacillen, Arch. f. experim. Path. und Pharm., Bd. XX, S. 309.

3) Zeitschrift f. Hygiene, Bd. XI.

4) Les poisons bactériens, Paris 1892, pag. 80.

5) Arch. f. Hygiene, Bd. 18, S. 318.

6) Lo Sperimentale, «Sezione biologica» 1895. 
sassen. Ich sah ferner, dass am kräftigsten immunisirend ein phosphorhaltiger Körper wirkte, welchen ich in Folge seiner allgemeinen Eigenschaften in die Klasse der Nucleoproteide reihte, in jene Klasse, deren präcise Charakterisirung schon vor einiger Zeit Hammarsten und Halliburton gegeben hatten. Ein gleichfalls mit vorzüglichem Impfvermögen ausgestatteter Körper wurde hierauf von Professor Lustig und mir $^{1}$ ) aus dem Pestbacillus isolirt. Ein anderer Mikroorganismus, den ich anlässlich einer unter den Schildkröten unseres Laboratoriums ausgebrochenen Epidemie isoliren konnte, gab mir schliesslich Gelegenheit, diese Substanzen chemisch näher zu untersuchen, indem auch er einen den beiden andern ähnlichen Körper lieferte.

Dieser Mikroorganismus, der dem Bacillus ranicidus von Ernst $\left.{ }^{2}\right)$ in Vielem ähnlich ist, war zu diesem Zwecke ausserordentlich geeignet, weil er sich auf jedem beliebigen Nährboden üppig entwickelt und weil er sich in Kalilauge rasch und vollständig löst.

Ich cultivirte diesen Mikroorganismus vorzugsweise auf Kartoffeln, indem ich mir derart mit Leichtigkeit eine sehr grosse Anzahl Bacterien verschaffen und die Colonien sammeln konnte, ohne befürchten zu müssen, gleichzeitig auch Theile des Nährbodens selbst mit wegzunehmen.

Ich wählte zu diesem Zwecke die grösseren Kartoffeln, schnitt sie nach entsprechender Waschung und Sterilisirung in Scheiben und benetzte deren Oberfläche mit einer aus AgarCultur und Wasser hergestellten Emulsion.

Drei Tage nach dem Verweilen im Thermostat bei $20^{\circ}$ waren die Scheiben mit einer wenigstens $2 \mathrm{~mm}$. hohen Schicht Reincultur bedeckt. Ich schabte nun deren oberflächlichsten Theil mit einem dünnen Hornspatel ab, darauf achtend, dass von der Kartoffel nichts mitgehe.

Auf diese Weise konnte ich stets genügend Mikroorga-

1) Deutsche med. Wochenschrift, 1897, Nr. 15. Risultati delle ricerche sulla peste ecc. Firenze 1897.

2) Ziegler's Beiträge 1890, S. 203. 
nismen sammeln, um 2-3 gr. der hier unten näher zu beschreibenden Substanz zu gewinnen.

Die von den Kartoffeln abgeschabten Culturen wurden hierauf sofort in 1\%iger Kalilauge gelöst und zwar derart, dass ich sie in einem Porzellanmörser, nach und nach mit der Kalilauge verrieb. Ich erhielt so eine zähe, schleimige Masse, welche sich in sehr lange und dünne Fäden ziehen liess.

Diese Masse schüttete ich nun in eine grosse Menge (2-3 Liter) schwacher $(1 / 2 \%)$ Essigsäurelösung. Unter fortwährendem Umrühren schieden sich hierauf dünne, weisse schleierartige Fetzen ab, die in kleinere Stücke zerfielen und sich in Form von grossen Flocken langsam zu Boden setzten. Ich sammelte diese Flocken auf ein Filter, wusch sie reichlich, vorerst mit angesäuertem Wasser, dann mit reinem Wasser, löste den Niederschlag von Neuem in schwachem Ammoniak, filtrirte durch eine dicke Schicht Papier mittelst der Luftpumpe und fällte schliesslich wieder mit Essigsäure. Bei einigen Versuchen löste und fällte ich die Substanz noch ein drittes Mal, allein durch dieses Vorgehen begann sich die Substanz bereits zu verändern, wie dies der reichere Phosphorgehalt bewies. Der Niederschlag wurde schliesslich mit Alkohol und Aether gewaschen und getrocknet. Ich erhielt auf diese Weise eine gelblichweisse körnige Masse, die zerrieben ein vollkommen weisses Pulver gab, löslich in alkalischen Flüssigkeiten. Die hervorragendsten Eigenschaften dieser Substanz sind: Unlöslich in den gewöhnlichen Lösungsmitteln und in destillirtem Wasser. Löslich in Alkalien; diese Lösung opalisirt und ist auch etwas schleimig, sobald sich eine grössere Menge in Lösung befindet; theilweise löslich in $10 \%$ iger Kochsalzlösung. Unlöslich in verdünnten Säuren. Fällt aus den alkalischen Lösungen bei Neutralisation oder schwacher Ansäuerung in Form von weissen Flocken. Fällt durch die Salze der Schwermetalle, durch Zinkchlorür, Silbernitrat, Alkohol, Tannin und ebenfalls durch Sättigung mit Ammonium- oder Magnesiumsulfat. Gibt die Millon'sche und die Xanthoproteinreaction. Mit Kalilauge und Kupfersulfat erhält man einen graugrünen Niederschlag, allein weder Reduction noch die Biuretreaction. 
Wenn man einige der durch Fällung mit Essigsäure erhaltenen Flocken in destillirtem Wasser suspendirt und kocht, so erleiden dieselben scheinbar keine Veränderung; wenn man aber hierauf die Flüssigkeit mit Natriumcarbonat leicht alkalisch macht und tüchtig durchschüttelt, so sieht man, wie sich die Flocken verändern und zerbröckeln. Die Flüssigkeit wird opalisirend, während sich nach und nach ein aus kleinen, den früheren unähnlichen Flöckchen bestehender Niederschlag zu Boden setzt. Wenn man hierauf abfiltrirt, so findet man, dass das Filtrat bei Ansäuerung nochmals einen Niederschlag gibt, während sich der auf dem Filter gebliebene Niederschlag nurmehr in concentrirten Säuren löst. Ich unterwarf diesen Rückstand auch der Pepsinverdauung, die ein positives Resultat ergab. Im ersten Filtrate wies ich ein ächtes Nuclein nach, welches dieselben Eigenschaften zeigte, wie das von Kossel aus den Blastomyceten gewonnene Nuclein.

Man erzielt also beim Kochen eine theilweise Coagulirung der Substanz und nach Versetzen mit Natriumcarbonat die Abspaltung des coagulirbaren Theiles von der in Lösung bleibenden Nucleingruppe.

Wenn man die direkt aus den Bacterien gewonnene Substanz mit künstlichem Magensaft verdaut, so erhält man ein Pepton und einen unlöslichen, an Phosphor reichen Rückstand.

Ich habe auch, genau nach Hammarsten, ${ }^{1}$ ) die Probe auf Nucleinbasen gemacht und ein positives Resultat erzielt, wodurch mir der Beweis für die Bildung von Nucleinbasen, in Folge der phosphorhaltigen Gruppe der Substanz, gegeben war.

Die Substanz hinterlässt wenig, aber an Phosphor reiche Asche. Ich fand auch Spuren von Schwefel, konnte aber dieses Element, in Folge seiner äusserst geringen Menge, quantitativ nicht bestimmen.

Bezüglich der physiologischen Eigenschaften dieser von mir isolirten Substanz will ich nur erwähnen, dass sie deut-

1) Zur Kenntniss der Nucleoproteide, Zeitschr. f. physiolog. Chemie, Bd. XIX, S. 19. 
lich die Halliburton'sche Probe ${ }^{1}$ ) gab. Eine kleine Menge der Substanz in einer 1\%igen Natriumcarbonatlösung gelöst und von dieser Lösung $10-20 \mathrm{ccm}$. einem Kaninchen (nicht Albino) in die Jugularis gespritzt, bewirkt nämlich sofortigen Tod des Thieres durch Gerinnung des Blutes im ganzen Gefässstamm. Die Substanz besitzt ferner ein kräftiges Impfvermögen, was ich bei sämmtlichen geimpften Thieren bestätigt fand, für welche der Mikroorganismus, der die fragliche Substanz lieferte, pathogen ist. Ganz kleine Mengen derselben genügen, um eine kräftige Immunität $\mathrm{zu}$ bewirken und um dem Blute der geimpften Thiere Schutz- und Heilwirkung zu verleihen.

Nach den mitgetheilten Kennzeichen glaube ich ohne Weiteres behaupten zu können, dass der von mir gewonnene Körper ein Nucleoproteid ist.

Und obschon ich nicht in der Lage war, eine vollständige Elementaranalyse desselben auszuführen, habe ich doch den Stickstoff- und Phosphorgehalt desselben bestimmt.

Zur Bestimmung des Stickstoffs bediente ich mich der auch von Andern zu diesem Zwecke gewählten Methode nach Kjeldahl und erhielt folgende Resultate:

\section{Präparat I (2 Fällungen).}

a) 0,6577 gr. Substanz neutralisirten $56,9 \mathrm{ccm}$. $1 / 10$ normal. $\mathrm{H}_{2} \mathrm{SO}_{4}$ $=12,11 \%$ Stickstoff.

b) $0,5201 \mathrm{gr}$. Substanz neutralisirten $45,1 \mathrm{ccm} .1 / 10$ normal. $\mathrm{H}_{2} \mathrm{SO}_{4}$ $=12,14 \%$ Stickstoff.

c) 0,3784 gr. Substanz neutralisirten $33,0 \mathrm{ccm}$. 1/10 normal. $\mathrm{H}_{2} \mathrm{SO}_{4}$ $=12,21 \%$ Stickstoff.

\section{Präparat II (2 Fällungen).}

d) 0,4121 gr. Substanz neutralisirten $35,3 \mathrm{ccm}$. ${ }^{1 / 10}$ normal. $\mathrm{H}_{2} \mathrm{SO}_{4}$ $=11,99 \%$ Stickstoff.

e) 0,3598 gr. Substanz neutralisirten $30,9 \mathrm{ccm} .{ }^{1 / 10}$ normal. $\mathrm{H}_{2} \mathrm{SO}_{4}$ $=12,02 \%$ Stickstoff.

Das procentuelle Mittel der beiden Versuche weist nur

1) Cfr. Halliburton, Nucleoproteids. Journ. of Physiology, Bd. 18, p. 306, und Nucleoalbumins and intravasculare coagulation, Journ. of Physiology, Bd. 17, p. 134. 
geringe Unterschiede auf: beim ersten Versuche erhielt ich im Mittel 12,15\%, beim zweiten im Mittel 12,005\% Stickstoff.

Es ist unentschieden, ob dieser Unterschied in wechselnden Verunreinigungen der Nucleoproteide, oder nach Cramer in einer, durch gewisse Unterschiede im Nährboden bedingten, verschiedenen Constitution der Mikroorganismen zu suchen sei. ${ }^{1}$ )

Ich muss auch bemerken, dass dieses Stickstoffprocent eher niedrig genannt werden muss, indem es kleiner als jenes aller anderen Proteide ${ }^{2}$ ) ist, mit Ausnahme jenes des Mucins. ${ }^{3}$ )

1) Cramer behauptet, dass der Stickstoffgehalt des Bacterienkörpers, in toto analysirt, je nach dem Nährboden, auf welchem der Mikroorganismus cultivirt wurde, variirt. Dieser Autor erhielt für $\mathbf{N}$ folgende Procentzahlen:

Bacterienspecies cultivirt

auf Agar unter Zusatz von 1\% Pepton $5 \%$ Pepton $5 \%$ Zucker

$\begin{array}{lllr}\text { Bacillus capsulatus von Pfeiffer. } & 12,18 & 12,32 & 9,43 \\ \text { Pneumoniebacillus . . . . . . } & 13,28 & 14,25 & 11,05 . \\ \text { Rhinosclerombacillus . . . . } & 12,63 & 13,46 & 10,76\end{array}$

Cholerabacillus . . im Mittel $\quad 7,26 \% \mathrm{~N}$.

Ich halte es für angezeigt, hier auch einige andere, durch die Elementaranalyse des Bacterienkörpers erhaltene Resultate mitzutheilen. So fanden: Brieger beim (fett- und aschefreien) Friedländer'schen Pneumoniebacillus einen Stickstoffgehalt von 9,75\%; Naegeli und Loew in einem gewöhnlichen Mikrococcus $10,65 \% \mathrm{~N}$. Vincenzi gibt für den Bacillus subtilis folgende wenig übereinstimmende Zahlen: 6.24\% $11,15 \%, 7,97 \%, 5,34 \%, 6,26 \%$; Kappes gibt für den Bacillus prodigiosus. $11,40 \% \mathrm{~N}$ und für den Xerosebacillus $12,12 \% \mathrm{~N}$ an. Djerzgowski und Rekowsky fanden im Diphteriebacillus $11,17 \% \mathrm{~N}$; Hammerschlag. in dem in Alkohol und Aether unlöslichen Theile des Tuberkelbacillus. $9,09 \% \mathrm{~N}$. Ich habe diese Zahlen dem Lehrbuche Flügge's entnommen.

2) Der Stickstoffgehalt der echten Nucleine schwankt zwischen $14,73 \%$ und $15,98 \%$ (Ne u me is ter, Lehrbuch der physiologischen Chemie; Jena 1897); jener der Proteide ist im Allgemeinen $15 \%$. Lilienfeld (Zur Chemie der Leucocyten, Zeitschr. f. physiol. Chemie, Bd. XVIII, 1893) fand für das Nucleoiston, welches ein Nucleoproteid der Leucocyten ist, im Mittel 16,86\% N. Hammarsten (Zur Kenntniss der Nucleoproteide, Zeitschr. f. physiol. Chemie, Bd. XIX) isolirte aus dem Pankreas ein sehr stickstoffreiches Nucleoproteid, dessen N-Gehalt im Mittel 17,39\% betrug.

3) Hammarsten (Lehrbuch d. physiol. Chemie, 1895, p. 39) gibt für den Stickstoffgehalt einiger Mucine folgende Zahlen an: Schneckenmucin $13,65 \% \mathrm{~N}$, Sehnenmucin $11,75 \% \mathrm{~N}$, Submaxillarmucin $12,32 \% \mathrm{~N}$. 
Zur Bestimmung des Phosphors veraschte ich die Substanz nach Liebig und wog den Phosphor als pyrophosphorsaures Magnesium, wie dies auch Halliburton, $\left.{ }^{1}\right) \mathrm{Pohl}^{5}$ ) und Lilienfeld (l. c.) gethan haben.

\section{Präparat I (2 Fällungen).}

a) 0,5439 gr. Nucleoproteid gaben 0,0226 gr. pyrophosphors. Magnesium $=1,16 \%$ Phosphor.

b) 0,2544 gr. Nucleoproteid gaben 0,0100 gr. pyrophosphors. Magnesium $=1,12 \%$ Phosphor.

\section{Präparat II (2 Fällungen).}

c) 0,8493 gr. Nucleoproteid gaben 0,0282 gr. pyrophosphors. Magnesium $=0,94 \%$ Phosphor.

d) 0,7921 gr. Nucleoproteid gaben 0,0287 gr. pyrophosphors. Magnesium $=1,01 \%$ Phosphor.

\section{Präparat III (3 Fällungen).}

e) 0,6583 gr. Nucleoproteid gaben 0,0431 gr. pyrophosphors. Magnesium $=1,83 \%$ Phosphor.

Diese Ziffern stimmen ziemlich gut überein. Die Erhöhung der Phosphorwerthe nach einer dritten Fällung hängt wahrscheinlich mit der dabei eintretenden theilweisen Zersetzung der Substanz zusammen, was auch Halliburton bei andern Nucleoproteiden fand. ${ }^{3}$ )

Das Gesagte zusammenfassend und die bei den Mikroorganismen der Cholera und Pest gemachten und erwähnten Erfahrungen im Auge behaltend, kann man schliessen, dass im Bacterienkörper Nucleoproteide vorhanden sind, die den

1) Halliburton, Nucleoproteids, Journ. of Physiology, Bd. 18, p. 306.

2) Poehl, Bemerkungen über künstlich dargestellte Eiweissnucleine, Zeitschr. f. physiol. Chemie, Bd. XIII, 1889.

3) Halliburton (l. c.) gibt für den Phosphorgehall der Nucleoproteide folgende Procentzahlen an:

$$
\begin{array}{cl}
\text { Nucleoproteid des Thymus . . . . . } 0,8 \% \\
» & \text { der Niere . . . . . } 0,37 \% \\
» & \text { der Leber . . . . . } .1,45 \% \\
» & \text { des Gehirns . . . . } .0,5 \% \\
» & \text { des Knochenmarks . . } 1,6 \% .
\end{array}
$$

Hammarsten (l. c.) fand im Nucleoproteid des Pankreas 4,44 bis $4,54 \% \mathrm{P}$. 
in den thierischen Geweben angetroffenen analog sind und sich von letzteren vielleicht nur durch einen geringeren Stickstoffgehalt unterscheiden. Wenn dem nun auch vom allgemeinen chemisch-physiologischen Standpunkt aus keinerlei Bedeutung zukommt, so hat es doch Wichtigkeit bezüglich der Immunitätsfrage. Wenn man nämlich weiss, dass es im Bacterienkörper Substanzen gibt, die mit hohem Immunisirungsvermögen ausgestattet sind, und ferner, dass diese Substanzen Nucleoproteide sind, d. h. Körper, deren hauptsächlichste chemische Eigenschaften man kennt, so steht Einem in der Erforschung solcher immunisirenden Substanzen und in den zur Isolirung und Herstellung derselben geeigneten Methoden ein ziemlich sicherer Wegweiser zur Verfügung.

Zum Schlusse habe ich noch eine Reihe von Versuchen bezüglich der Art und Weise, wie sich dieses Nucleoproteid :gegenüber den verschiedenen Farbstoffen verhält, angestellt, da ich annahm, dass dies für das Studium des mikrochemischen Verhaltens der den lebenden Organismus bildenden Körper von allgemeinem Interesse sein könnte.

Ehe ich jedoch diese Versuche und deren Resultate schildere, muss ich der Tinctionstheorie im Allgemeinen und der Art und Weise, in welcher die bezüglichen Thatsachen interpretirt werden, einige Worte widmen.

Die allgemein gültige Hypothese ist die folgende. Die Fähigkeit eines Körpers, sich mit einer bestimmten Farbsubstanz mehr oder weniger dauernd zu färben ist eine molekulare Erscheinung, ähnlich den Lösungsphänomenen im Allgemeinen, und abhängig von der Constitution des zu färbenden Körpers und von jener der Farbensubstanz und dès Vehikels selbst. $\mathrm{Zu}$ chemischen Wechselwirkungen zwischen dem zu färbenden Körper und der Farbensubstanz kommt es im Allgemeinen nicht (Theorie von Otto Witt). ${ }^{1}$ )

1) Auch Heine (Die Mikrochemie der Mitose, zugleich eine Kritik mikrochemischer Methoden. Zeitschr. f. physiol. Chemie, Bd. XXI, 1896, p. 495) ist der Ansicht, dass es nicht zulässig sei, zur Erklärung der Tinctionserscheinungen chemische Processe heranzuziehen und anzunehmen, dass die Moleküle des Farbstoffes mit den Molekülen des zu färbenden 
In der Färberei-Industrie sagt man, eine Farbe sei beständig, wenn der gefärbte Körper die einmal aufgenommenen Farbpartikelchen an keines der gewöhnlichen Lösungsmittel wieder abgibt. Auch in der mikroskopischen Technik spricht man von Dauerfärbungen und auch von Electivfärbungen; z. B. wenn gewisse Zelltheile sich in einer Mischung von Farbsubstanzen nur mit gewissen dieser Substanzen färben (Biondi'sche Methode) und die Farbe auch dann behalten, wenn sie in eine Flüssigkeit gebracht werden, die für diese Farbstoffe ein kräftiges Lösungsmittel bildet (z. B. salzsaurer Alkohol, wie man ihn bei der Methode nach Flemming verwendet). Alles das bildet aber einen Complex von ganz unbestimmten und unvollständigen Kenntnissen, während meiner Ansicht nach die Chemie der verschiedenen Zellbestandtheile durch ein rationelles Studium des Färbvermögens der verschiedenen Zellen nur gewinnen könnte. Meiner Ansicht nach ist es auch gefehlt, von Affinität eines Zellelements bezüglich einer gegebenen Farbsubstanz in absolutem Sinne zu sprechen ${ }^{1}$, so wie man z. B. sagt, dass das Chromatin des Nucleus Affinität besitze für die basischen Anilinfarben. Der Irrthum wird sofort offenbar, so wie man sieht, dass eine basophile Substanz sich mit gewissen sauren Farben vorzüglich $\mathrm{zu}$ färben vermag.

Man muss vielmehr die Affinität eines und desselben Körpers gegenüber verschiedenen Farbsubstanzen und verschiedenen Lösungsmitteln vergleichend in Betracht ziehen. So z. B. sagt uns die Methode nach Biondi, die uns sonst

Körpers eine chemische Verbindung eingehen. Bezüglich dessen, was dieser Autor über die Basicität oder Acidität der verschiedenen Farbstoffe sagt, muss ich hinzufügen, dass in dieser Beziehung, seitdem alle gegenwärtig benützten Farbstoffe vollkommen bekannt sind, keinerlei Ungewissheit mehr möglich ist.

1) Die Benennung Affinität ist allgemein gebräuchlich bei denjenigen, die sich mit dem Studium der Färbungserscheinungen befassen, und wird damit die Eigenschaft eines Körpers bezeichnet, die Farbmoleküle besser und beständiger zurückzuhalten als ein anderer. In diesem speciellen Sinne benütze auch ich diesen Ausdruck, ohne aber mit demselben in irgend einer Weise die Bedeutung zu verknüpfen, die ihm in der Chemie zukommt. 
so gute Dienste leistet, nicht, dass das Chromatin des Nucleus Affinität besitzt für das Methylgrün und das Cytoplasma für das Säurefuchsin (thatsächlich können wir das Cytoplasma auch mit Methylgrün und den Nucleus mit Säurefuchsin färben), sondern sie sagt uns, dass das Chromatin für das Methylgrün eine grössere Affinität zeigt als für das Säurefuchsin, während beim Protoplasma das Gegentheil der Fall ist.

Die mehr oder weniger beständige Färbung und die Wahlverwandtschaft sind nichts Anderes, als das Resultat der zwischen dem zu färbenden Körper und den Farbsubstanzen sowie den verschiedenen Lösungsmitteln bestehenden Affinität. Man könnte sagen, dass für einen gewissen $\mathrm{zu}$ färbenden Körper ein gegebenes Lösungsmittel und eine gewisse Farbsubstanz ein Färbungscoefficient besteht, welcher das Resultat des Verhältnisses bildet, in welchem die Coefficienten der Löslichkeit der Farbsubstanz in dem zu färbenden Körper und der Löslichkeit in dem Lösungsmittel zu einander stehen. Von diesem Coefficienten (von dem ich nicht weiss, ob er mathematisch bestimmt werden könnte) hängt nun die mehr oder weniger grosse Beständigkeit und die Electivität einer gegebenen Färbung ab.

Das Färbungsvermögen eines Körpers wird sich also aus einem vergleichenden Studium der Färbungen ergeben, welche man bei dem Körper durch verschiedene Farbsubstanzen und I.ösungsmittel $\mathrm{zu}$ erzielen vermag.

Auf diese Weise bieten sich uns vier Fälle dar:

a) Der Körper färbt sich entweder intensiv in concentrirten Lösungen und gibt die einmal aufgenommenen Farbmoleküle an das Lösungsmittel, in eine grosse Menge desselben gebracht, nicht $a b$; oder

b) er gibt intensiv gefärbt (z. B. durch Verweilen in einer mit einem anderen Lösungsmittel bereiteten Lösung) an das Lösungsmittel sämmtliche Farbmoleküle $a b$ und bleibt alsdann farblos; oder aber

c) der zu färbende Körper entzieht einer verdünnten und entsprechend bereiteten Lösung sämmtliche Farbmoleküle derart, dass, während er selbst sich intensiv färbt, die Lösung vollkommen entfärbt wird; oder schliesslich 
d) der Körper ist nicht im Stande, die Farbmoleküle weder verdünnten noch concentrirteren Lösungen $\mathrm{zu}$ entziehen, und bleibt also auch in letzteren vollkommen ungefärbt.

Bemerkenswerth hierbei ist, dass im Falle a) auch die unter c) oder d) aufgestellten Möglichkeiten zutreffen können, während im Falle b) nur noch die Möglichkeit add) eintreten kann, dagegen die sub b) und c) gleichzeitig niemals beobachtet werden können.

Und so sagt man also, bei Benutzung desselben Lösungsmittels, ein Körper besitze für einen gegebenen Farbstoff eine grössere Affinität, als der Farbstoff selbst gegenüber dem Lösungsmittel, sobald die in a) und c) oder auch die in a) und d) angeführten Erscheinungen gleichzeitig zutreffen, und dass der Unterschied zwischen der Affinität des Körpers für den Farbstoff und der Affinität des Lösungsmittels für denselben Farbstoff in den Fällen a) und c) grösser und in den Fällen a) und d) kleiner sein wird.

Ebenso wird man sagen, ein Körper besitze für einen gegebenen Farbstoff geringere Affinität als der Farbstoff selbst für das Lösungsmittel, sobald die Fälle sub b) und d) gleichzeitig zutreffen.

Im vorliegenden Falle habe ich bezüglich des von mir isolirten Nucleoproteids eine Anzahl Farbstoffe auf ihr Verhalten gegenüber den zwei Lösungsmitteln, Wasser und Alkohol, geprüft.

Bezüglich jedes der Farbstoffe stellte ich vier Versuche an und zwar zwei mit Wasser und zwei mit Alkohol. Zu den Versuchen selbst wählte ich aus dem durch Ansäuerung mittelst Essigsäure gewonnenen Nucleoproteidniederschlage die grösseren Flocken und behandelte dieselben nun der Reihe nach wie folgt :

1. Ich tauchte einige derselben in die concentrirten wässerigen Farblösungen, liess sie darin eine gewisse Zeit und wusch sie hierauf reichlich mit destillirtem Wasser;

2. andere Flocken wieder brachte ich in ganz verdünnte wässerige Lösungen; 
3. wieder andere, bereits gefärbte Flocken brachte ich in absoluten Alkohol und wechselte denselben so lange, bis derselbe keine Farbe mehr aufnahm;

4. andere, mittelst absoluten Alkohols vorher entwässerte Flocken schliesslich brachte ich in schwache alkoholische Farblösungen.

Die Resultate dieser Versuche finden sich in nachfolgender Tabelle zusammengefasst ${ }^{1}$ ):

\begin{tabular}{|c|c|c|c|c|}
\hline \multirow{3}{*}{$\begin{array}{c}\text { Verwendeter } \\
\text { Farbstoff. }\end{array}$} & \multicolumn{4}{|c|}{ Lösungsmittel } \\
\hline & \multicolumn{2}{|c|}{ Wasser } & \multicolumn{2}{|c|}{ Alkohol } \\
\hline & $\begin{array}{l}\text { Das Nucleo- } \\
\text { proteid gibt die } \\
\text { Farbmoleküle } \\
\text { an Wasser } \\
\text { ab, oder nicht. }\end{array}$ & $\begin{array}{c}\text { Das Nucleo- } \\
\text { proteid entzieht } \\
\text { dieFarbmoleküle } \\
\text { dem Wasser, } \\
\text { oder nicht. }\end{array}$ & $\begin{array}{l}\text { Das Nucleo- } \\
\text { proteid gibt die } \\
\text { Farbmoleküle } \\
\text { an Alkohol } \\
\text { ab, oder nicht. }\end{array}$ & $\begin{array}{l}\text { Das Nucleo- } \\
\text { proteid entzieht } \\
\text { dieFarbmolekule } \\
\text { dem Alkohol, } \\
\text { oder nicht. }\end{array}$ \\
\hline Fuchsin (basisch) & nein & ja & ja & nein \\
\hline Salpetersaures Rosanilin . & nein & ja & ja & nein \\
\hline Jodgrün & nein & ja & ja & nein \\
\hline Methylgrün & nein & ja & ja & nein \\
\hline Rubin S. . . . . & ja & nein & nein & ja \\
\hline Lichtgrün. . . . & ja & nein & nein & ja \\
\hline Eosin (wasserlöslich) & nein & nein & nein & ja \\
\hline Eosin (alkohollöslich). & nein & ja & ja & nein \\
\hline Orange G. . . . & ja & nein & ja & nein \\
\hline Tropaeolin 0000 & ja & nein & ja & nein \\
\hline Bordeaux . . . . & ja & nein & ja & nein \\
\hline Congoroth. . . . & nein & nein & nein & ja \\
\hline Stilbenroth . . . & nein & nein & nein & ja \\
\hline Sulfomagnium . . & nein & nein & nein & ja \\
\hline Methylenblau. . . & nein & ja & nein & ja \\
\hline Thionin ..... & nein & ja & nein & ja \\
\hline Safranin & nein & nein & nein & nein \\
\hline Neutralroth. & nein & nein & nein & nein \\
\hline Indulin (wasserlöslich) & ja & nein & ja & nein \\
\hline Nigrosin(masserlöslich) & ja & nein & ja & nein \\
\hline
\end{tabular}

1) Diese Resultate wurden auch durch andere Versuche bestätigt. So z. B. brachte ich einige (entwässerte) Flocken des Nucleoproteids in eine Mischung wässeriger Lösungen zweier Farbstoffe, für welche das Nucleoproteid ganz verschịedene Affinität zeigte, und stets konnte ich 
Aus dieser Tabelle ist das Färbungsvermögen (nach den von mir oben erörterten Principien) des von mir isolirten Nucleoproteids, gegenüber den verschiedenen Farbstoffen und gegenüber Wasser und Alkohol als Lösungsmittel, ersichtlich.

Diese verschiedenen Grade des Färbungsvermögens, welche mit der chemischen Constitution des Körpers im Zusammenhang scheinen und z. B. denjenigen der Löslichkeit in verschiedenen Menstruen analog sind, können dazu dienen, die untersuchte Substanz zu charakterisiren und besser zu bestimmen.

Diese das Färbungsvermögen des von mir isolirten Nucleoproteids betreffenden Eigenschaften kann man wie folgt zusammenfassen :

1. Der Körper besitzt für die basischen Farbstoffe des Rosanilins, für das alkohollösliche Eosin (Kaliumsalz des Methyläthers des Tetrabromfluoresceins) tür die Thiazine eine weit grössere Affinität als diejenige, welche zwischen den genannten Substanzen und dem Wasser besteht;

2. er besitzt für die Tetrazofarbstoffe (Gruppe des Congoroths), für die Safranine (basische Derivate. der Azine), für das wasserlösliche Eosin (Kaliumsalz des T'etrabromflucresceins) eine nur um Weniges grössere Affinität als diejenige, welche zwischen den genannten Substanzen und dem Wasser besteht;

3. er besitzt für die Sulfonverbindungen der Rosaniline, für die Azofarbstoffe, für die wasserlöslichen Induline eine kleinere Affinität, als zwischen diesen Substanzen und dem Wasser besteht;

beobachten, dass sich das Nucleoproteid nur mit jenem Farbstoff färbte, für welchen es grössere Affinität besass. So färbte es sich z. B. in der Biondi'schen Lösung grün. - Lilienfeld (Ueber die Wahlverwandtschaft der Zellelemente $\mathrm{zu}$ gewissen Farbstoffen. Arch. f. Anat. und Physiol., Physiol. Abth. 1893, pag. 395) bestätigt die gleiche Thatsache, indem er sagt: «dass die Kernsubstanzen, Nucleoproteide, Nucleine, Nucleinsäuren immer den basischen, die Eiweisskörper des Zellleibes immer den sauren Farbstoff aus dem Farbengemisch auswählen. 
4. er besitzt für die Sulfonderivate des Rosanilins, für die Thiazine, für das wasserlösliche Eosin eine weit grössere Affinität, als zwischen diesen Substanzen und dem Alkohol besteht;

5 . er besitzt für die Safranine eine nur um Weniges grössere Affinität, als zwischen diesen Farbstoffen und dem Alkohol besteht;

6. er besitzt für die basischen Farbstoffe des Rosanilins, für das alkohollösliche Eosin, für die Azofarbstoffe, für die wasserlöslichen Induline eine kleinere Affinität, als zwischen den genannten Substanzen und dem Alkohol besteht.

Florenz, im November 1897. 